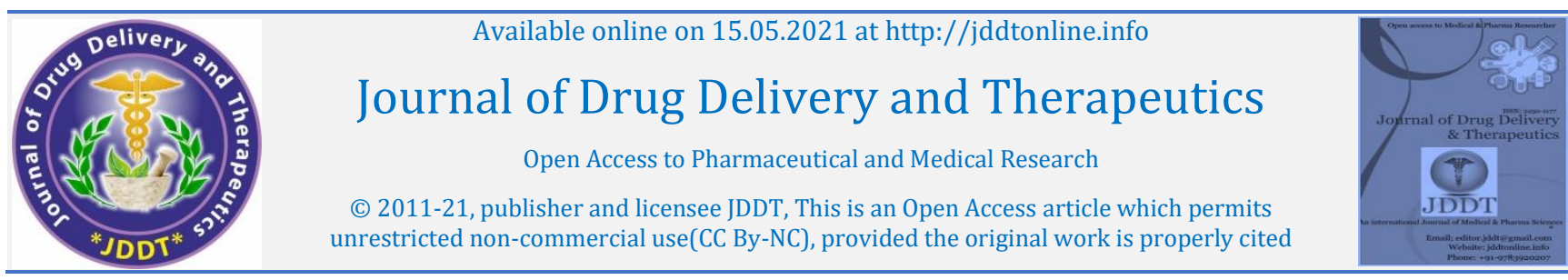

\title{
Formulation and Optimization of Zolmitriptan Orodispersible Tablets
}

\author{
T.V. Hari Hara Nadh*, P. Sivaram Kumar, M. Venkata Ramana, N. Rama Rao \\ Department of Pharmaceutics, Chalapathi Institute of Pharmaceutical Sciences, Lam, Guntur, Andhra Pradesh-522034, India
}

\begin{tabular}{ll}
\hline Article Info: & \\
\hline & Article History: \\
\hline & $\begin{array}{l}\text { Received 13 March 2021; } \\
\text { Accepted 29 April 2021; } \\
\text { Available online 15 May 2021 }\end{array}$
\end{tabular}

Cite this article as:

Hari Hara Nadh TV, Sivaram Kumar P, Venkata Ramana M, Rama Rao N, Formulation and Optimization of Zolmitriptan Orodispersible Tablets, Journal of Drug Delivery and Therapeutics. 2021; 11(3):50-57

DOI: http://dx.doi.org/10.22270/jddt.v11i3.4703

\section{*Address for Correspondence:}

T.V. Hari Hara Nadh, Department of Pharmaceutics, Chalapathi Institute of Pharmaceutical Sciences, Lam, Guntur, Andhra Pradesh-522034, India

\begin{abstract}
Zolmitriptan is a selective 5-hydroxytryptamine receptor agonist reported for the acute migraine treatment, having poor water solubility leads to poor bioavailability. In the present study, attempt to improve the bioavailability of zolmitriptan with the help of PVP K-30 using the microwave irradiation method. The zolmitriptan and PVP K- 30 in 1:1 ratio was subjected to microwave irradiation for different times such as $60,80,100,120$ seconds at 650 watts. Characterization of solid dispersion was done by drug content, XRD, FTIR, DSC. FTIR analysis demonstrated there are no compatibility issues. XRD studies prove that the solid dispersion was in amorphous form. DSC studies prove that solid dispersion was amorphous based on the intensity of peaks. The prepared dispersion was made into orodispersible tablets by direct compression. The optimization of these formulations was carried out by using $3^{2}$ factorial designs on Design Expert 10.0 software. In order to examine the effect of independent variables Crospovidone ( $\left.\mathrm{X}_{1}\right)$ croscarmellose sodium $\left(\mathrm{X}_{2}\right)$, and combined effect of independent variables $3^{2}$ factorial design was selected. In this design, two responses such as disintegration time and \% drug release were evaluated, and experimental trials are performed for all 9 formulations. For all formulations, the precompression and post-compression parameters were studied. Based upon the model optimized formulation (C1 and C2) was obtained having the disintegration time $(34.4 \pm 0.84$ and $39.8 \pm 0.91)$ and \%drug release $(98.7 \pm 0.42$ and $93.2 \pm 0.46)$ respectively.
\end{abstract}

Keywords: Zolmitriptan, Solid dispersion, Microwave irradiation, Crospovidone, Croscarmellose sodium.

\section{INTRODUCTION:}

The FDA defines ODT as "a solid dosage form containing the active ingredients or medicinal substance that disintegrate rapidly, within a second when placed in the mouth."1. the time required for the disintegration of ODTs varies from seconds to minutes 2 .

Orodispersible tablets are also called orally disintegrating tablets. Mouth dissolving tablets, rapid dissolving tablets, rapimelt, fast-dissolving tablets, quick disintegrating.

Zolmitriptan is a selective 5-hydroxytryptamine receptor subtype agonist approved for the acute treatment of migraine attacks with or without aura in adults. Zolmitriptan is having $40 \%$ oral bioavailability 3 . The therapeutic effectiveness of a drug relies on bioavailability and ultimately upon the dissolution of drug molecules. Zolmitriptan is having poor solubility ${ }^{4}$, one of the promising is to increase the rate of dissolution of the zolmitriptan solid dispersion technique is employed. Several techniques such as kneading, solvent evaporation, and hot-melt extrusion, microwave irradiation, etc. for the preparation of solid dispersions.

The microwave irradiation technique is having several advantages such as rapid volumetric heating, no overheating at the surface, addressable heating, energy-saving, and low operating cost. Furthermore, the key advantage of not using organic solvents is the avoidance of any risk obtained by residual solvents $\mathbf{5}$

In this study zolmitriptan, solid dispersion was prepared by microwave irradiation technique using polyvinylpyrrolidone (PVP K-30) as a carrier. PVP is a promising carrier for improving the bioavailability of the drugs.

\section{MATERIALS AND METHODS}

Zolmitriptan API was a gift sample from hetero labs PVT Ltd, polyvinyl pyrrolidone K-30 (Loba chemicals), Mannitol (fisher Scientifics) and Avicel $\mathrm{p}^{\mathrm{H}}-102$, Croscarmellose sodium USP-NF (AC-Di- Sol) (FMC biopolymer), Crospovidone (FMC biopolymer), Aspartame (Loba chemicals), Magnesium stearate (Ferro industries).

\section{Standard calibration curve for zolmitriptan}

Zolmitriptan Stock solution was prepared by using $0.1 \mathrm{~N}$ hydrochloric acid. Solutions ranging from $1-5 \mu \mathrm{g} / \mathrm{ml}$ were prepared in $10 \mathrm{ml}$ volumetric flasks. Absorbance was measured for each solution at $\lambda \max 225 \mathrm{~nm}$. The graph was plotted for absorbance versus concentration of zolmitriptan 6.

\section{Fourier transform infrared (FT-IR) studies}

The compatibility between the drug and excipients used in the formulation was evaluated using Bruker alpha-T, and 
analyzed by Opus. These studies were carried to the physical mixture, solid dispersion, and optimized formulation. These samples for analysis were prepared by gently mixing the test sample with $\mathrm{KBr}$ and prepare the pellets with pellet press ${ }^{7}$.

\section{Differential scanning calorimetry (DSC) studies}

The DSC thermogram of pure zolmitriptan and prepared dispersion was obtained to find out the possible interactions of excipients with the drug was obtained using TAinstruments DSC-Q20 and analyzed by using TA explorer. samples were weighed $(2-5 \mathrm{mg})$ and sealed in aluminium pans and heated up to $300^{\circ} \mathrm{C}$ with the help of zero air, the heating rate is $10^{\circ} \mathrm{C} / \mathrm{min}^{7}$.

\section{X-ray diffractometer (XRD) studies}

The crystallographic properties of pure zolmitriptan and solid dispersion were studied using an X-Ray diffractometer, $\mathrm{Cu}$ radiation. The diffractometer was run at a scanning speed of $2 \% / \mathrm{min}$. The position and intensities of diffraction peaks were considered for the identification and comparison of crystallinity of the pure zolmitriptan and solid dispersion (SD3) ${ }^{8}$.

\section{Phase solubility studies}

Phase solubility studies were carried out as per the method reported by Higuchi and Connors. An excess amount of zolmitriptan was added to $10 \mathrm{ml}$ of water containing different concentrations of polyvinylpyrrolidone (PVP K-30) in a stoppered flask. All the above solutions with different concentrations of PVP K-30 were shaken in a bath shaker for $24 \mathrm{hrs}$. After shaking the solutions were filtered through a membrane filter of $0.45 \mu \mathrm{m}$ and their absorbance was observed at $225 \mathrm{~nm}{ }^{9}$. The apparent stability constants (Ks) were calculated from the phase solubility diagram, by using the following equation

$\mathrm{K}_{\mathrm{S}}=$ slope $/ \mathrm{S}_{0}(1-$ slope $)$

Where $\mathrm{S}_{0}=$ solubility of zolmitriptan in water

\section{Preparation of solid dispersion by microwave} irradiation

Solid dispersion of zolmitriptan using PVP K-30 was prepared by microwave irradiation method in a 1:1 ratio. A homogenous paste was prepared by mixing PVP K-30 and zolmitriptan with a small amount of ethanol in mortar. The paste formed was irradiated in a microwave at 650 watts for 60, 80, 100, 120sec labelled as SD1, SD2, SD3, SD4 10. The glass plate was placed at room temperature for solidification, solid dispersion was collected and stored in a desiccator for $24 \mathrm{hrs}$ and then the product was pulverized and the powder was then passed through sieve.no 60 and store the dispersion in a desiccator $\mathbf{1 1}$.

\section{Assay of solid dispersion}

The solid dispersion equivalent to $10 \mathrm{mg}$ was added in $10 \mathrm{ml}$ $0.1 \mathrm{~N}$ hydrochloric acid in a volumetric flask. It was placed in a water bath shaker for 1 hour. The solution was then filtered through membrane filters of $0.45 \mu \mathrm{m}$ and spectrophotometrically analyzed at $\lambda \max 225 \mathrm{~nm} 12$.

\section{Formulation development and preparation of zolmitriptan orodispersible tablets}

Zolmitriptan SD3 orodispersible tablets were prepared by the direct compression method. To optimize the formulation a selected three-level, two-factor experimental design $\left(3^{2}\right.$ factorial design) describes the proportion in which the independent variables Crospovidone and Croscarmellose sodium were used in the formulation of zolmitriptan orodispersible tablets. Disintegration Time and percent drug release were selected as dependent variables, the experimental design layout as shown in table 1 . The three levels of factor X1 (Crospovidone) at a concentration of 2\%, $4 \%, 6 \%$. Three levels of factor X2 (Croscarmellose sodium) at a concentration of $0.5 \%, 2.75 \%, 5 \%$ were taken as the rationale for the design of the zolmitriptan orodispersible tablets. Totally nine zolmitriptan orodispersible tablets formulations are prepared randomly as per the design to employ selected combinations of the two factors i.e, X1, X2 as per $3^{2}$ Factorial and evaluated to find out the significance of combined effects of X1, X2 to select the best combination and the concentration required to achieve the desired disintegration time (response 1) and \%drug release (response 2) of the dosage forms. The precompression tests are performed. All the ingredients of the formulations F1-F9, C1 and C2 are passed through sieve no 60, thoroughly mixed, and compressed using $6 \mathrm{~mm}$ flat punches. Excipients required for the Formulation of zolmitriptan orodispersible tablets table 2. Tablets were stored in well-closed and moisture-proof containers.

Table 1: Experimental design layout

\begin{tabular}{|c|c|c|c|c|c|}
\hline $\begin{array}{l}\text { Formulation } \\
\text { code }\end{array}$ & Run & $\begin{array}{l}\text { Coded Factor } \\
\mathrm{X}_{1}\end{array}$ & Coded Factor $\mathrm{X}_{2}$ & $\begin{array}{l}\text { Factor } \\
X_{1}: \text { cp \% }\end{array}$ & $\begin{array}{l}\text { Factor } \\
\mathrm{X}_{2} \text { : ccs \% }\end{array}$ \\
\hline F1 & 1 & 0 & 0 & 4 & 2.75 \\
\hline F2 & 2 & -1 & 1 & 2 & 5 \\
\hline F3 & 3 & -1 & -1 & 2 & 0.5 \\
\hline $\mathrm{F} 4$ & 4 & 1 & 0 & 6 & 2.75 \\
\hline F5 & 5 & 0 & -1 & 4 & 0.5 \\
\hline F6 & 6 & -1 & 0 & 2 & 2.75 \\
\hline F7 & 7 & 1 & 1 & 6 & 5 \\
\hline F8 & 8 & 0 & 1 & 4 & 5 \\
\hline F9 & 9 & 1 & -1 & 6 & 0.5 \\
\hline
\end{tabular}


Table 2: Formulation Table for zolmitriptan orodispersible tablets

\begin{tabular}{|l|l|l|l|l|l|l|l|l|l|l|l|}
\hline Ingredient & F1 & F2 & F3 & F4 & F5 & F6 & F7 & F8 & F9 & C1 & C2 \\
\hline $\begin{array}{l}\text { Solid Dispersion } \\
\text { (SD3) (mg) }\end{array}$ & 10 & 10 & 10 & 10 & 10 & 10 & 10 & 10 & 10 & 10 & 10 \\
\hline Aspartame (mg) & 0.75 & 0.75 & 0.75 & 0.75 & 0.75 & 0.75 & 0.75 & 0.75 & 0.75 & 0.75 & 0.75 \\
\hline Crospovidone (\%) & 4 & 2 & 2 & 6 & 4 & 2 & 6 & 4 & 6 & 4.85 & 2.33 \\
\hline $\begin{array}{l}\text { Croscarmellose } \\
\text { sodium (\%) }\end{array}$ & 2.75 & 5 & 0.5 & 2.75 & 0.5 & 2.75 & 5 & 5 & 0.5 & 3.79 & 5.0 \\
\hline Mannitol (mg) & 35 & 35 & 35 & 35 & 35 & 35 & 35 & 35 & 35 & 35 & 35 \\
\hline Talc (mg) & 0.75 & 0.75 & 0.75 & 0.75 & 0.75 & 0.75 & 0.75 & 0.75 & 0.75 & 0.75 & 0.75 \\
\hline $\begin{array}{l}\text { Magnesium stearate } \\
\text { (mg) }\end{array}$ & 1.5 & 1.5 & 1.5 & 1.5 & 1.5 & 1.5 & 1.5 & 1.5 & 1.5 & 1.5 & 1.5 \\
\hline $\begin{array}{l}\text { Avicel PH-102 (q.s- } \\
\text { 100 mg) }\end{array}$ & q. s & q. s & q. s & q. s & q. s & q. s & q. s & q. s & q. s & q. s & q. s \\
\hline
\end{tabular}

\section{Characterization of prepared formulations}

\section{Hardness}

The hardness of the tablets was tested by using lab India automatic tablet Hardness Tester (Model No.TH1050S). A tablet hardness of about 19.61-39.22 $\mathrm{N}$ is considered adequate for mechanical stability 13 .

\section{Friability}

The friability of the tablets was measured by using a lab India tablet friability tester (Model No. FT1020). Tablets were taken, Weighed and Initial weight was noted $\left(\mathrm{W}_{\mathrm{o}}\right)$ are dedusted in a drum for a fixed time (25 rpm for 4 minutes) and weighed (W) again. Percentage friability was calculated 13.

\section{Content Uniformity}

In this test, 20 tablets were crushed in mortar and pestle, and weighed powder contains equivalent to $10 \mathrm{mg}$ of drug was taken and dissolved in $10 \mathrm{ml}$ of $0.1 \mathrm{~N} \mathrm{HCL}$ and the solution then filtered through membrane filters of $0.45 \mu \mathrm{m}$, after suitable dilution with $0.1 \mathrm{~N} \mathrm{HCL}$, the drug content was spectrophotometrically analyzed at $\lambda \max 225 \mathrm{~nm}{ }^{12}$.

\section{Wetting time}

To measure the Wetting time of the Tablet, a piece of Tissue paper folded twice was placed in a small petri dish (Internal Diameter is $6.5 \mathrm{~cm}$ ) containing $5 \mathrm{ml}$ of Distilled water. A Tablet was placed on the paper, and the time for complete wetting of the tablet was measured in seconds ${ }^{13}$.

\section{In-vitro disintegration}

The in-vitro dissolution was carried out using a lab India tablet disintegrating tester (Model No. DT1000). Six tablets are placed in each tube of disintegrating test apparatus were measured at $37 \pm 0.5^{\circ} \mathrm{C}$ using $900 \mathrm{ml}$ of $0.1 \mathrm{~N} \mathrm{HCL}{ }^{14}$.

\section{In-vitro drug release profile}

The in-vitro dissolution was carried out using paddle apparatus, the dissolution medium was $0.1 \mathrm{~N} \mathrm{HCL}$, the temperature was maintained at $37 \pm 0.5{ }^{\circ} \mathrm{C}$, and $50 \mathrm{rpm}$. Aliquots of $5 \mathrm{ml}$ samples were withdrawn at predetermined time intervals of 5, 10, 15, 20, 25, 30 minutes. And maintain sink condition with the same dissolution media. The withdrawn samples were filtered through a membrane filter of $0.45 \mu \mathrm{m}$ and analyzed by using a UV-spectrophotometer at $225 \mathrm{~nm} 15$.

\section{RESULTS AND DISCUSSION}

The standard calibration curve for zolmitriptan is constructed in $0.1 \mathrm{~N}$ HCL. The zolmitriptan follows beer lamberts law over a concentration range of $1-5 \mathrm{mg} / \mathrm{ml}$ and the regression coefficient were found to be 0.998 . Phase solubility studies were carried out as per Higuchi and Connors and $A_{L}$ type of curve was obtained, based on the phase solubility studies 1:1 drug-polymer ratio employed for the preparation of solid dispersion. All the solid dispersion by varying the exposure time (SD1-SD4) were prepared and the percentage yield was found to be in the range of 95 $98 \%$ and the all the prepared dispersions was assayed and results were found to be $80 \%, 82 \%, 95 \%$, and $80 \%$ respectively. Out of all the prepared dispersions based upon assay results, SD3 was selected for preparing orodispersible tablets.

\section{Fourier transform infrared (FT-IR) studies}

The FTIR spectrum of pure zolmitriptan exhibited characteristic signals at $3349 \mathrm{~cm}^{-1} \quad(\mathrm{NH}$ stretching vibrations), $2974 \mathrm{~cm}^{-1}$ (C-H stretching vibrations), $1732 \mathrm{~cm}^{-1}$ (C=0 stretching vibrations), $1479 \mathrm{~cm}^{-1} \quad(\mathrm{C}=\mathrm{C}$ stretching vibrations), $1369 \mathrm{~cm}^{-1}$ (C-N stretching vibrations) and 1042 $\mathrm{cm}^{-1}$ (C-O stretching vibrations). The results obtained are in confirmation with literature $\mathbf{1 6}^{16}$. The solid dispersion (SD3) of zolmitriptan exhibit characteristic signals at $3349 \mathrm{~cm}^{-1}(\mathrm{~N}-\mathrm{H}$ stretching vibrations), $2923 \mathrm{~cm}^{-1}$ (C-H stretching vibrations), $1734 \mathrm{~cm}^{-1}$ (C=0 stretching vibrations), $1458 \mathrm{~cm}^{-1} \quad(\mathrm{C}=\mathrm{C}$ stretching vibrations), $1370 \mathrm{~cm}^{-1}$ (C-N stretching vibrations) and $1259 \mathrm{~cm}^{-1}$ (C-O stretching vibrations). This shows that all the characteristic peaks that were present in the spectra of pure zolmitriptan replicate almost similar regions in the spectra of solid dispersion (SD3) indicating that there is no significant interaction between the drug and the carrier. The FTIR spectra of pure zolmitriptan and solid dispersion (SD3) were shown in (figure 1). 


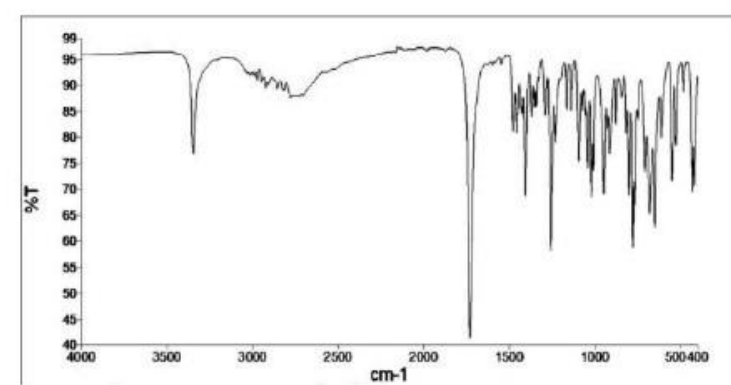

(a)

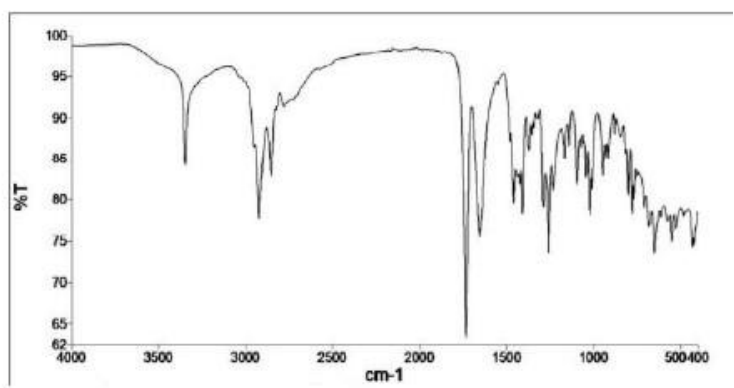

(b)

Figure 1: (a) FTIR for pure zolmitriptan (b) FTIR for solid dispersion of zolmitriptan

\section{Differential scanning calorimetry (DSC) studies.}

DSC thermogram for pure zolmitriptan shows sharp endotherm at point $138.44{ }^{\circ} \mathrm{C}$, (figure 2 (a)) indicates that it

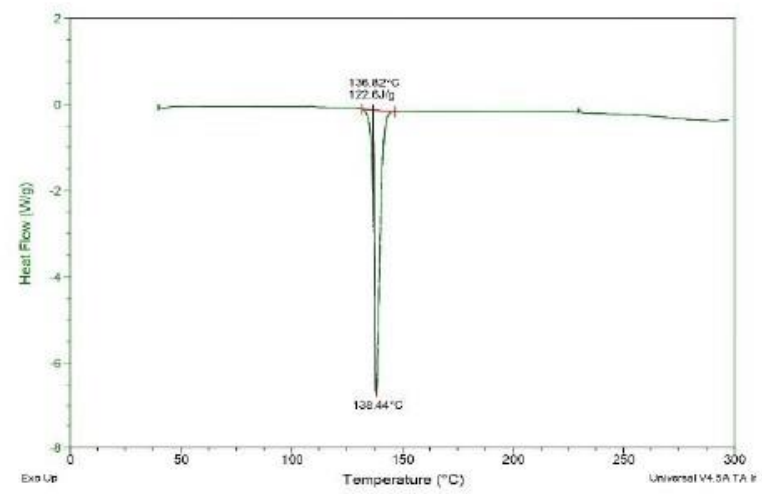

(a) was in crystalline form, zolmitriptan solid dispersion (SD3) generate a broad peak at $84.54{ }^{\circ} \mathrm{C}$, (figure 2 (b)) indicates that zolmitriptan in dispersion is converted from crystalline form to amorphous form.

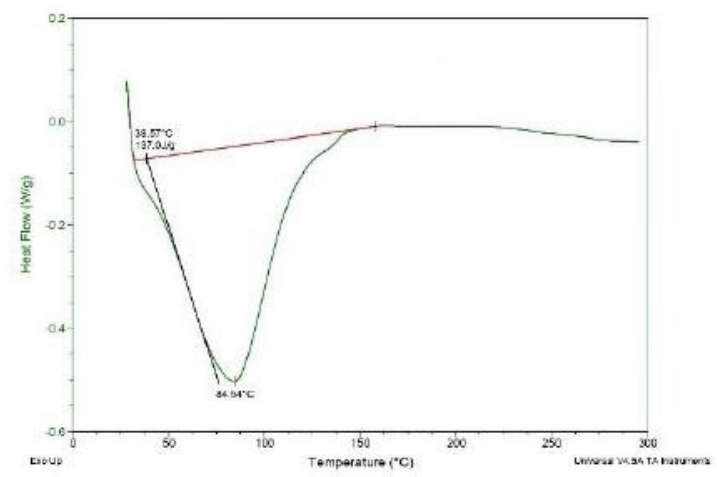

(b)

Figure 2: (a) pure zolmitriptan (b) solid dispersion of zolmitriptan

\section{X-ray diffractometer (X-RD) studies}

The XRD patterns of pure zolmitriptan show sharp intensity peaks at a diffraction angle of $2 \theta$ at 16.18, 18.71, and 23.42 (figure 3 (a)) indicates the crystalline nature of the drug. The XRD patterns of solid dispersion of zolmitriptan show broad

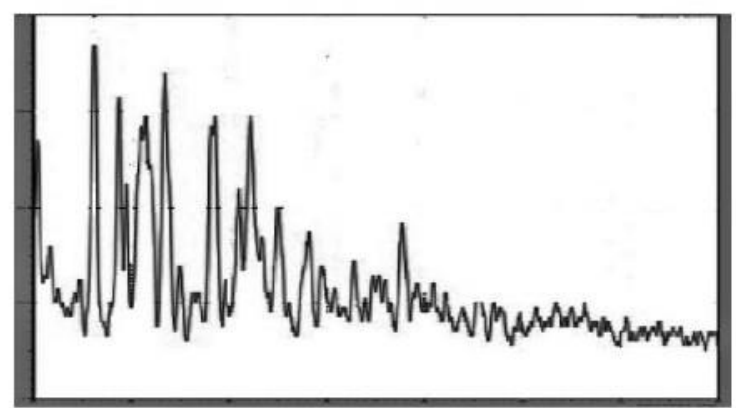

(a) intensity peaks at diffraction angles of $2 \theta$ at 19.98, 20.88, and 21.96 (figure 3 (b)) indicates that the solid dispersion of zolmitriptan was in amorphous form. In solid dispersion the integrated intensity is lower than the pure form of zolmitriptan further indicates the conversion of amorphous form.

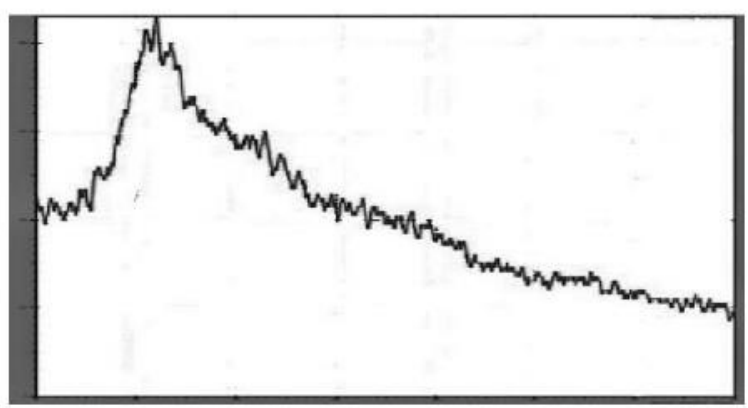

(b)

Figure 3: (a) pure zolmitriptan (b) solid dispersion 


\section{Characterization of formulations}

The pre-compression and post-compression characteristics of the formulations were carried the pre-compression studies are the angle of repose, bulk density, tapped density, Carr's compressibility index, and Hausner's ratio under the limits (table 3) and post-compression studies such as hardness, friability, content uniformity, wetting time, disintegration time, and percent drug release were also under the limits (table 4).

\section{Experimental design and statistical data analysis}

Experimental results indicated that the disintegration time and percent drug release depend upon the concentration of the Crospovidone and croscarmellose sodium. The ratio of Crospovidone and croscarmellose sodium was optimized by using $3^{2}$ factorial designs using Design Expert 10.0 software. Orodispersible tablets were obtained with disintegrating time and percent Drug release in the range of $14 \pm 0.3$ to $56 \pm 0.9$ and $79.5 \pm 0.8$ to $99.1 \pm 0.91$ respectively. A significant quadratic model $(\mathrm{p}<0.05)$ for disintegration $\left(\mathrm{Y}_{1}\right)$ duration and percent drug release $\left(\mathrm{Y}_{2}\right)$ of orodispersible tablets were found during statistical analysis of data to optimize orodispersible tablets. Polynomial models have been generated with multiple linear regression analyses for all response variables (MLRA). This polynomial equation describes the effect of independent variables on dependent variables was expressed as follows

$$
\mathrm{Y}=\mathrm{b}_{0}+\mathrm{b}_{1} \mathrm{X}_{1}+\mathrm{b}_{2} \mathrm{X}_{2}+\mathrm{b}_{12} \mathrm{X}_{1} \mathrm{X}_{2}+\mathrm{b}_{11} \mathrm{X}_{1}^{2}+\mathrm{b}_{22} \mathrm{X}_{2}^{2}
$$

In the preceding equation (1), Y represents the dependent variable (response). $b_{o}$ is the intercept and arithmetic mean responses of nine runs and $b_{1}, b_{2}, b_{12}, b_{11}$, and $b_{22}$ are the estimated coefficients for the corresponding factors $X_{1}, X_{2}$, $\mathrm{X}_{1} \mathrm{X}_{2}, \mathrm{X}_{1}{ }^{2}, \mathrm{X}_{2}{ }^{2}$ respectively. The main effect of $\mathrm{X}_{1}$ and $\mathrm{X}_{2}$ represents the average result of changing one variable at a time from its low to high value. The integration terms $\mathrm{X}_{1} \mathrm{X}_{2}$ show how disintegration time, percent drug release changes when two variables are simultaneously varied. The quadratic effect is determined by polynomial terms $\mathrm{X}_{1} 2$ and $\mathrm{X}_{2}{ }^{2}$. The sign of coefficients in the polynomial equation represents the synergistic effects (denoted by +ve sign) and antagonistic effect (denoted by -ve sign) on responses. Predicted $\mathrm{R}^{2}$ indicates how well the model fits the data. The predicted $R^{2}$ and the adjusted $R^{2}$ should be within 0.20 of each other otherwise there may be a problem with either the data or the model. A probability value $(p<0.05)$ was used to indicate how significant is the corresponding coefficient. Adequate precision is a signal-to-noise ratio. It compares the range of the predicted value at the design points to the average prediction error. Ratios greater than 4 indicate adequate model discrimination. One-way ANOVA was applied to estimate the significance of the model $(p<0.05)$.

The polynomial equation relating to disintegration time $\left(\mathrm{Y}_{1}\right)$ $\mathrm{Y}_{1}=$ Disintegration time

$\mathrm{Y}_{1}=33.22-9.33 \mathrm{X}_{1}-9.67 \mathrm{X}_{2}+0.7500 \mathrm{X}_{1} \mathrm{X}_{2}+4.67 \mathrm{X}_{1}{ }^{2}-3.33 \mathrm{X}_{2}{ }^{2}$

$\left[\mathrm{R}^{2}=0.9384 ; \mathrm{F}-\right.$ value $=9.15 ; p<0.050$, adjusted $\mathrm{R}^{2}=0.8358$, predicted $\mathrm{R}^{2}=0.2625$, adequate precision $\left.=9.2755\right]$

From the above model equation, F-value (9.15) confirmed that the model was significant and values of prob $>F$ indicate that the model terms were significant $(p=0.05)$ it was observed that the terms $\mathrm{X}_{1}, \mathrm{X}_{2}, \mathrm{X}_{1}{ }^{2}, \mathrm{X}_{2}{ }^{2}$ have significant effect on disintegrating time $(p<0.05)$.

The polynomial equation related to percent Drug release $\left(\mathrm{Y}_{2}\right)$

$\mathrm{Y}_{2}=$ Percent drug release

$\mathrm{Y}_{2}=99.67-5.83 \mathrm{X}_{1}+1.83 \mathrm{X}_{2}-0.500 \mathrm{X}_{1} \mathrm{X}_{2}-10.50 \mathrm{X}_{1}{ }^{2}-4.50 \mathrm{X}_{2}{ }^{2}$

$\mathrm{R}^{2}=0.9536, \mathrm{~F}$-value $=12.33$, adjusted $\mathrm{R}^{2}=0.8763$, Predicted $\mathrm{R}^{2}=0.4436$, adequate precision $\left.=9.6658\right]$

From the above model equation, F-value (12.33) confirmed that the model was significant and values of prob $>\mathrm{F}$ indicate that the model terms were significant $(p=0.05)$ it was observed that the terms $\mathrm{X}_{1}, \mathrm{X}_{2}, \mathrm{X}_{1}{ }^{2}, \mathrm{X}_{2}{ }^{2}$ have a significant effect on \%Drug release $(p<0.05)$.

The influence of the combined effect of independent variables on selected responses was further investigated by response surface methodology. Response surface methodology gives three-Dimensional response surface plots and two-Dimensional contour plots. The threeDimensional response surface plots are very useful in learning about the main effects and interaction effects of the independent variables (factors) and the two-dimensional contour plots give a visual representation of values of the response ${ }^{17}$. The contour plots and 3D response plots were generated by the software helped to visualize the information of the nine experimental runs on each response. The results show that when the concentration of Crospovidone(X1) and Croscarmellose sodium (X2) increases the disintegration time decreases and increases the percent drug release.

Table 3: Precompression parameters for the formulation of F1-F9 and optimized formulation C1-C2.

\begin{tabular}{|l|l|l|l|l|l|}
\hline $\begin{array}{l}\text { Formulation } \\
\text { code }\end{array}$ & Angle of repose & Bulk density & Tapped density & $\begin{array}{l}\text { Carr's } \\
\text { compressibility }\end{array}$ & Hausner's Ratio \\
\hline F1 & $23.98 \pm 1.79$ & $0.26 \pm 0.03$ & $0.31 \pm 0.05$ & $14.16 \pm 1.2$ & $1.16 \pm 0.01$ \\
\hline F2 & $24.21 \pm 1.61$ & $0.26 \pm 0.03$ & $0.31 \pm 0.05$ & $13.42 \pm 0.16$ & $1.15 \pm 0.02$ \\
\hline F3 & $26.31 \pm 1.25$ & $0.27 \pm 0.4$ & $0.29 \pm 0.04$ & $5.54 \pm 1.12$ & $1.05 \pm 0.01$ \\
\hline F4 & $25.14 \pm 1.02$ & $0.26 \pm 0.03$ & $0.29 \pm 0.04$ & $8.82 \pm 0.09$ & $1.09 \pm 0.01$ \\
\hline F5 & $24.98 \pm 0.71$ & $0.27 \pm 0.03$ & $0.28 \pm 0.04$ & $6.01 \pm 1.26$ & $1.06 \pm 0.01$ \\
\hline F6 & $26.41 \pm 0.97$ & $0.27 \pm 0.04$ & $0.31 \pm 0.05$ & $10.75 \pm 1.12$ & $1.12 \pm 0.01$ \\
\hline F7 & $28.58 \pm 1.22$ & $0.25 \pm 0.03$ & $0.29 \pm 0.04$ & $11.40 \pm 2.32$ & $1.12 \pm 0.02$ \\
\hline F8 & $24.81 \pm 1.89$ & $0.27 \pm 0.04$ & $0.31 \pm 0.05$ & $11.43 \pm 0.16$ & $1.12 \pm 0.02$ \\
\hline F9 & $26.56 \pm 1.08$ & $026 \pm 0.03$ & $0.29 \pm 0.05$ & $9.67 \pm 3.33$ & $1.10 \pm 0.04$ \\
\hline C1 & $26.24 \pm 0.87$ & $0.28 \pm 0.03$ & $0.32 \pm 0.04$ & $11.81 \pm 0.16$ & $1.13 \pm 0.02$ \\
\hline C2 & $28.51 \pm 1.21$ & $0.27 \pm 0.03$ & $0.31 \pm 0.04$ & $11.53 \pm 0.16$ & $1.13 \pm 0.02$ \\
\hline
\end{tabular}

All the data were expressed as the mean \pm standard deviation $(\mathrm{n}=3)$ 
Table 4: Post compression parameters for the formulation of F1-F9 and optimized formulation C1-C2.

\begin{tabular}{|c|c|c|c|c|c|c|}
\hline $\begin{array}{l}\text { Formulation } \\
\text { code }\end{array}$ & $\begin{array}{l}\text { Hardness } \\
\left(\mathrm{Kg} / \mathrm{cm}^{2}\right)\end{array}$ & $\begin{array}{l}\text { Friability } \\
\text { (\%) }\end{array}$ & $\begin{array}{l}\text { Content } \\
\text { uniformity }\end{array}$ & $\begin{array}{l}\text { Wetting } \\
\text { time }\end{array}$ & $\begin{array}{l}\text { Disintegration } \\
\text { time (sec) } \\
\left.\text { (response } Y_{1}\right)\end{array}$ & $\begin{array}{l}\text { percent drug } \\
\text { release } \\
\left(\text { response } Y_{2}\right)\end{array}$ \\
\hline F1 & $35.9 \pm 0.152$ & $0.62 \pm 0.07$ & $98.6 \pm 0.67$ & $27.2 \pm 1.54$ & $31.8 \pm 0.98$ & $98.1 \pm 0.75$ \\
\hline F2 & $36.8 \pm 0.21$ & $0.62 \pm 0.04$ & $97.8 \pm 1.04$ & $32.6 \pm 0.59$ & $36.3 \pm 0.51$ & $91.1 \pm 0.75$ \\
\hline F3 & $35.4 \pm 0.18$ & $0.65 \pm 0.09$ & $98.2 \pm 1.45$ & $43.4 \pm 1.24$ & $56.3 \pm 0.51$ & $87.5 \pm 0.83$ \\
\hline F4 & $34.8 \pm 0.21$ & $0.68 \pm 0.04$ & $98.1 \pm 1.14$ & $31.4 \pm 1.81$ & $34.5 \pm 0.54$ & $81.3 \pm 0.51$ \\
\hline F5 & $34.5 \pm 0.11$ & $0.66 \pm 0.02$ & $99.3 \pm 0.78$ & $39.4 \pm 1.41$ & $41.6 \pm 0.81$ & $93.5 \pm 0.83$ \\
\hline F6 & $36.1 \pm 0.47$ & $0.64 \pm 0.02$ & $97.1 \pm 1.24$ & $38.2 \pm 1.26$ & $43.8 \pm 0.98$ & $98.3 \pm 0.51$ \\
\hline F7 & $35.8 \pm 0.25$ & $0.63 \pm 0.02$ & $99.4 \pm 1.04$ & $11.2 \pm 1.56$ & $14.6 \pm 0.81$ & $81.3 \pm 0.51$ \\
\hline F8 & $36.4 \pm 0.23$ & $0.61 \pm 0.01$ & $98.6 \pm 0.58$ & $18.4 \pm 1.25$ & $20.8 \pm 0.75$ & $97.6 \pm 0.51$ \\
\hline F9 & $36.7 \pm 0.54$ & $0.62 \pm 0.02$ & $99.1 \pm 1.54$ & $27.5 \pm 1.54$ & $31.3 \pm 0.513$ & $78.6 \pm 0.51$ \\
\hline C1 & $38.4 \pm 0.51$ & $0.65 \pm 0.01$ & $98.1 \pm 1.15$ & $28.4 \pm 0.84$ & $34.4 \pm 0.84$ & $98.7 \pm 0.42$ \\
\hline $\mathrm{C} 2$ & $38.1 \pm 0.67$ & $0.67 \pm 0.01$ & $96.5 \pm 0.98$ & $31.2 \pm 0.75$ & $39.8 \pm 0.91$ & $93.2 \pm 0.46$ \\
\hline
\end{tabular}

All the data were expressed as the mean \pm standard deviation. Hardness, friability, content uniformity, and wetting time ( $\mathrm{n}=3$ ) and for disintegration time and percent drug release $(n=6)$.

Table 5: Optimized formulation

\begin{tabular}{|c|c|c|c|c|c|c|c|c|}
\hline \multirow{2}{*}{$\begin{array}{l}\text { Formulation } \\
\text { code }\end{array}$} & \multirow[t]{2}{*}{ X1 } & \multirow[t]{2}{*}{$\mathrm{X} 2$} & \multicolumn{2}{|c|}{ Predicted value } & \multicolumn{2}{|c|}{ Observed value } & \multicolumn{2}{|c|}{ Error } \\
\hline & & & $\begin{array}{l}\text { Disintegrati } \\
\text { on time } \\
\text { (sec) }\end{array}$ & $\begin{array}{l}\text { percent } \\
\text { drug } \\
\text { release }\end{array}$ & $\begin{array}{l}\text { Disintegration } \\
\text { time (sec) }\end{array}$ & $\begin{array}{l}\text { percent } \\
\text { drug release }\end{array}$ & $\begin{array}{l}\text { Disintegrati } \\
\text { on time } \\
\text { (sec) }\end{array}$ & $\begin{array}{l}\text { percent } \\
\text { drug } \\
\text { release }\end{array}$ \\
\hline $\mathrm{C} 1$ & 4.859 & 3.798 & 32 & 99 & $34.4 \pm 0.84$ & $98.7 \pm 0.42$ & 2 & -1 \\
\hline $\mathrm{C} 2$ & 2.336 & 5.00 & 36 & 91 & $39.8 \pm 0.91$ & $93.2 \pm 0.46$ & 3 & 2 \\
\hline
\end{tabular}

The disintegration time and percent drug release were expressed as mean \pm standard deviation $(n=3)$.

\section{Optimization of formulation variables}

Several predicted ratios of independent variables were generated using the software after applying the maximum and minimum values for each factor and response. To evaluate the optimization capability of generated models, two formulations ( $\mathrm{C} 1$ and $\mathrm{C} 2$ ) were selected to prepare orodispersible tablets which were expected to provide desired values of parameters (table 5). Numerical optimization was carried out by studying the desirability function, goals were kept in range, and constraints were applied. The desirability function of the selected optimization formulation was found to be near values indicating the suitability of the formulations. The graphical optimization was carried out by constraints overlay graphs (Figure 5) after applying the constraints for each factor and response ${ }^{18}$. Characterization of two selected formulations indicated that observed values of the batch were close to values predicted by software. Formulations had disintegration time and drug release with minimum error values indicating mathematical models obtained from the $3^{2}$ factorial design were well fitted.

\section{Stability Studies}

Accelerated stability studies ensure the acceptability of the dosage form. Storage conditions affect the stability of the preparation. Accelerated Stability studies were carried out for 1 month to check the disintegration time and percent drug release of the tablets. The conditions were maintained at $40^{\circ} \mathrm{C} \pm 2^{\circ} \mathrm{C}$ and $75 \% \mathrm{RH} \pm 5 \%$ for 1 month in the stability chamber. After the completion of 1 month, the samples were collected from the stability chamber and tested for hardness, friability, content uniformity, disintegration time, wetting time, percent drug release was studied (table 6). 


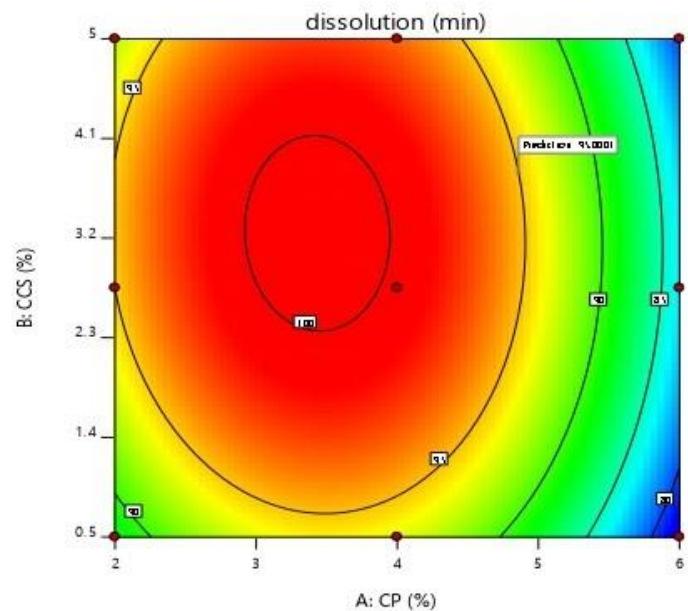

(a)

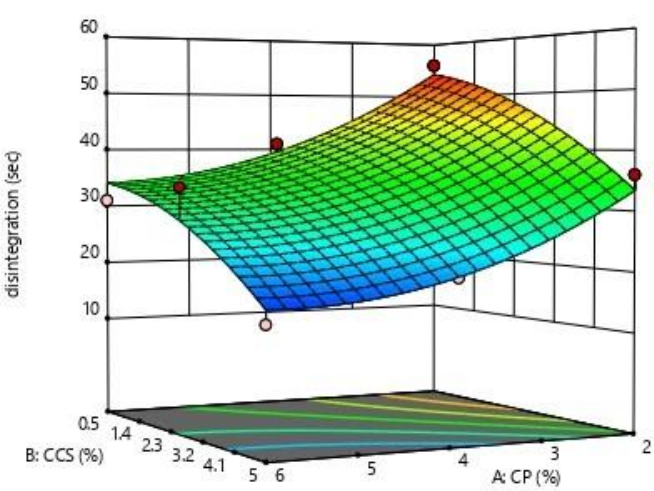

(c)

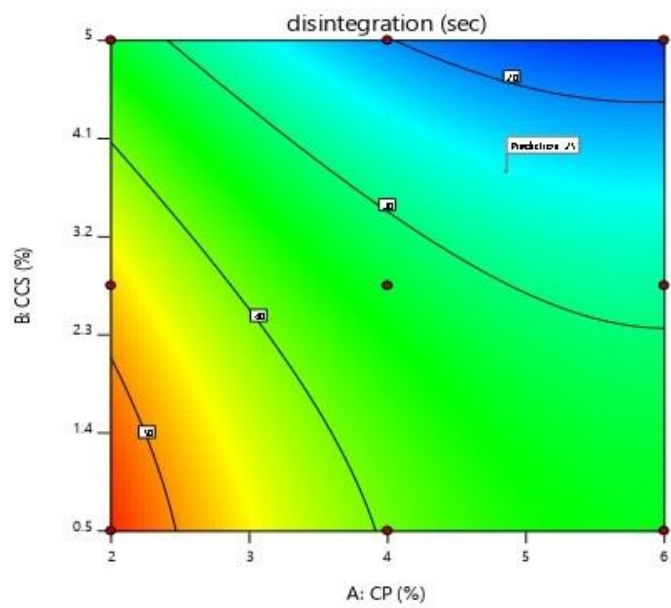

(b)

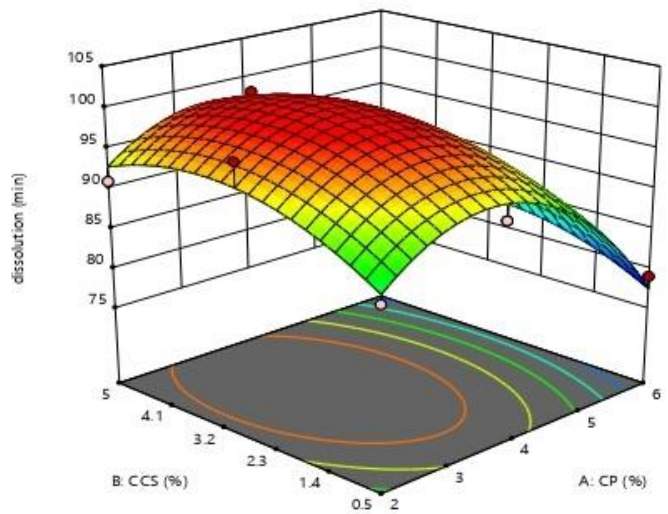

(d)

Figure 4: (a) contour plot for dissolution (b) contour plot for disintegration (c) 3D surface plot for disintegration (d) 3D surface plot for dissolution.

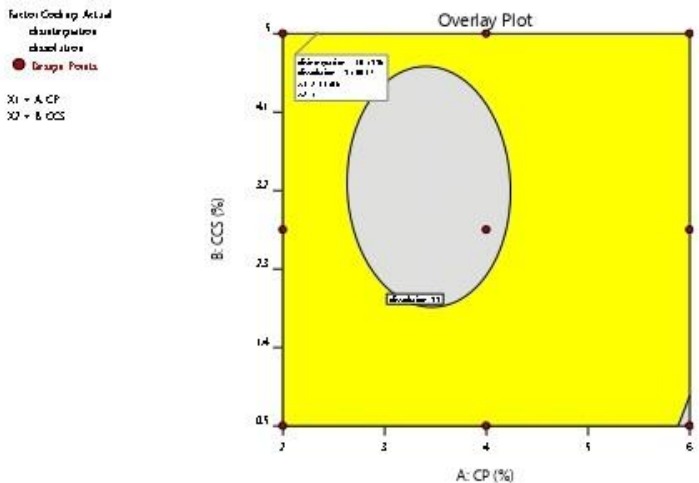

(a)

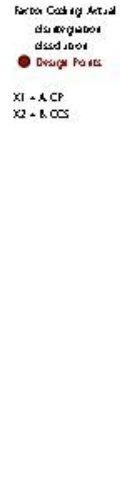

Figure 5: (a) Overlay plot for dissolution (b) over lay plot for disintegration

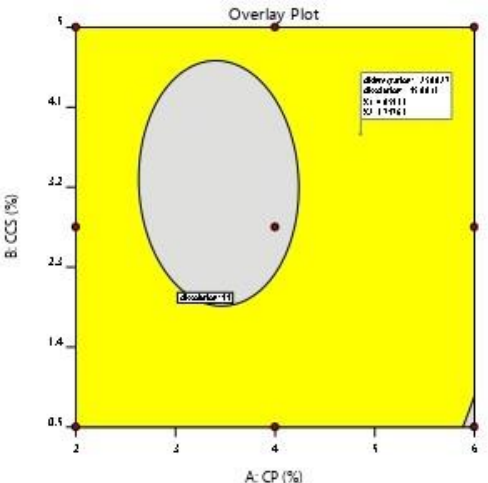

(b)

Table 6: Accelerated stability studies

\begin{tabular}{|l|l|l|l|l|l|l|l|}
\hline S.no & Formulation & $\begin{array}{l}\text { Hardness } \\
\mathbf{( N )}\end{array}$ & $\begin{array}{l}\text { Friability } \\
\mathbf{( \% )}\end{array}$ & $\begin{array}{l}\text { Content } \\
\text { uniformity }\end{array}$ & $\begin{array}{l}\text { Wetting } \\
\text { time }\end{array}$ & $\begin{array}{l}\text { Disintegra-on } \\
\text { time (sec) }\end{array}$ & $\begin{array}{l}\text { Percent drug } \\
\text { release }\end{array}$ \\
\hline 1 & $\mathrm{C} 1$ & $37.9 \pm 0.48$ & $0.66 \pm 0.02$ & $97.5 \pm 0.98$ & $27.9 \pm 0.79$ & $33.9 \pm 0.59$ & $97.9 \pm 0.62$ \\
\hline 2 & $\mathrm{C} 2$ & $38.3 \pm 0.74$ & $0.68 \pm 0.02$ & $96.9 \pm 0.91$ & $31.8 \pm 0.58$ & $38.8 \pm 0.48$ & $92.8 \pm 0.86$ \\
\hline
\end{tabular}

All the data were expressed as mean \pm standard deviation ( $\mathrm{n}=3$ ) 


\section{CONCLUSION}

The three-level factorial design has been used successfully to study the interaction among formulation variables and to obtain the appropriate design space. The confirmation formulation trails reveal the applicability of the model for the development of orodispersible tablets of zolmitriptan. The confirmation formulations were subjected to accelerated stability studies for 1 month. The results indicate the prepared tablets are stable with no significant difference in evaluation parameters. The overall attempt to improve the bioavailability of zolmitriptan by making microwave irradiated solid dispersion and formulating orodispersible tablets results in improve bioavailability.

\section{Conflict of interest:}

The author declares that they have no conflict of interest.

\section{REFFERENCES}

1. Hazee Peera N, Lohithasu D, Sahoo SK, Santhosh Naidu KMK VAK. Formulation development and evaluation of oral disintegrating tablets of zolmitriptan. Der Pharm Lett. 2013; 5(2):324-32.

2. Dey P, Maiti S. Orodispersible tablets : A new trend in drug delivery. J Nat Sci Biol Med. 2010; 1(1):2-5.

3. Mostafa DAE, Khalifa MKA, Gad SS. Zolmitriptan Brain targeting via intranasal route using solid lipid nanoparticles for migraine therapy : Formulation, Characterization, in-vitro and In-vivo Assessment. Int J Appl Pharm. 2020; 12(2):1-8.

4. Alhalaweh A, Andersson S, Velaga SP. Preparation of zolmitriptan - chitosan microparticles by spray drying for nasal delivery. Eur J Pharm Sci. 2009; 38:206-14.

5. Moneghini M, Bellich B, Baxa P, Princivalle F. Microwave generated solid dispersions containing Ibuprofen. Int J Pharm. 2008; 361(1-2):125-30.

6. Humaira S, Munde MR, Road OJ. Validated UV spectroscopic method for estimation of zolmitriptan from tablet formulations.
Int J Biomed Adv Res. 2010; 01(03):82-7.

7. Frizon F, Eloy J de O, Donaduzzi CM, Mitsui ML, Marchetti JM. Dissolution rate enhancement of loratadine in polyvinylpyrrolidone $\mathrm{K}-30$ solid dispersions by solvent methods. Powder Technol [Internet]. 2013; 235:532-9.

8. Maurya D, Belgamwar V, Tekade A. Microwave induced solubility enhancement of poorly water soluble atorvastatin calcium. J Pharm Pharmacol. 2010; 1599-606.

9. Higuchi T CK. Phase-solubility techniques. In: Reilley CN. Adv Anal Chem Instrum. 2018; 7(3):180-2.

10. Ranpise NS, Kulkarni NS, Mair PD, Ranade AN. Improvement of water solubility and in vitro dissolution rate of aceclofenac by complexation with $\beta$-cyclodextrin and hydroxypropyl- $\beta$ cyclodextrin. Pharm Dev Technol. 2010; 15(April 2009):64-70.

11. Raina A, Sciences P. Microwave induced solubility enhancement of poorly water-soluble drug simvastatin using poloxamer 188 by microwave irradiation method. Int J Pharm Sci Res. 2020; 11(4):1643-52.

12. Morade VB, Daga VR, Malpure PR. Formulation and Evaluation of Mouth Dissolving Tablets of Zolmitriptan. Asian J Pharm Sci Technol. 2018; 8(2):43-51.

13. Gunda RK, Kumar JNS, Satyanarayana V, Batta S, Harika CM. Formulation Development and Evaluation of Carbamazepine Fast Dissolving Tablets. J Pharm Res. 2016; 10(5):216-25.

14. Naga J, Kumar S, Gunda RK. Design, Formulation and Evaluation of Pravastatin Fast Dissolving Tablets . 2018;9(1):15-22.

15. Egla M, Abd SN, Hammid A. Design of Zolmitriptan Liquisolid Orodispersible Tablets and Their In Vitro Evaluation. J Chem Pharm Res. 2016; 8(11):232-42.

16. Nandy BC, Gupta AK, Mittal A, Pradesh M. Design and development of solid dispersion system of zolmitriptan. J Biomed Pharm Res. 2013; 2(5):7-13.

17. Kumar A, Pal D, Santra K. Artocarpus heterophyllus L . seed starch-blended gellan gum mucoadhesive beads of metformin HCl. Int J Biol Macromol. 2014; 65:329-39.

18. Godbole MD, Sabale PM, Mathur VB. Development of lamivudine liposomes by three- level factorial design approach for optimum entrapment and enhancing tissue targeting. J Microencapsul. 2020; 0(0):1-14 